\title{
Media Development Model-Based Learning Detection Assisted Guided Macromedia Flash for Improving the Visual Thinking Ability Student SMP
}

\author{
Tut Wuri Handayani * Edi Syahputra Mulyono \\ University of Medan, Jl. Willem Iskandar Psr. V Medan, Indonesia
}

\begin{abstract}
This study aimed to describe; 1) The validity, practicality, and effectiveness of media-assisted learning of mathematics developed macromedia flash; 2) Improvement of visual thinking abilities of students were given a guided discovery-based learning models by using the media-assisted learning of mathematics developed macromedia flash. This research is development. This study was conducted in two phases, namely the development stage media-assisted learning of mathematics macromedia flash using 4-D model of development and piloting stage media-assisted learning of mathematics developed macromedia flash-3 class VIII SMP Negeri 2 Morawa. From the test results I and II trials obtained: 1) the validity of the developed mediapembelajaran valid, practicality of learning media has practically met the criteria in terms of: a) the validity of instructional media according to the experts; b) Questionnaire practicality test developed mathematical learning media belongs in the practical value of at least $76 \%$ of test practicality and effectiveness of instructional media effectively meets the criteria in terms of: a) mketuntasan classical student learning; b) The response of students to the study of mathematics positive media; c) the use of the ideal time. And 2) an increase in visual thinking ability of students to trials I of 68.89 increased to 73.61 on trial II. b) Questionnaire practicality test developed mathematical learning media belongs in the practical value of at least $76 \%$ of test practicality and effectiveness of instructional media effectively meets the criteria in terms of: a) mketuntasan classical student learning; b) The response of students to the study of mathematics positive media; c) the use of the ideal time. And 2) an increase in visual thinking ability of students to trials I of 68.89 increased to 73.61 on trial II. b) Questionnaire practicality test developed mathematical learning media belongs in the practical value of at least $76 \%$ of test practicality and effectiveness of instructional media effectively meets the criteria in terms of: a) mketuntasan classical student learning; b) The response of students to the study of mathematics positive media; c) the use of the ideal time. And 2) an increase in visual thinking ability of students to trials I of 68.89 increased to 73.61 on trial II.
\end{abstract}

Keywords : Development of Mathematics Learning Media, Macromedia Flash, Visual Thinking Ability

DOI: $10.7176 / \mathrm{JEP} / 10-20-08$

Publication date:July $31^{\text {st }} 2019$

\section{INTRODUCTION}

Education is one of the very important factors in increasing human resources for the betterment of the nation. The progress of a nation is determined by the quality of human resources and quality of human resources depends on the quality of education. One study that is considered important to improve and develop the quality of human resources is a mathematics education (according to Sujono, 1988: 10). Regarding the role of mathematics, he also said that:

In the development of modern civilization, mathematics plays an important role because with the help of all science mathematics become more perfect. Mathematics is an efficient tool that is required by all the sciences. And without the help of mathematics everything will have no significant progress.

In line with the above the Vision in learning mathematics by Hasratuddin (2015: 137) is "Vision of Mathematics education today is mastery of concepts in mathematics used to solve problems. While the vision of the future of mathematics education is to provide opportunities to develop the mindset, confidence, beauty, objective attitude, and open. Mathematics as a basic science is an abstract object. Their abstract properties can lead to difficult students understand the subject matter of mathematics. To help students understand abstract concepts in mathematics learning need to be assisted with props using objects - objects of concrete or other learning media. Teachers are not enough to simply have knowledge of media education,

The importance of development of instructional media is done to increase and produce a new learning products. In addition it aims to produce media that is able to solve problems in the classroom, because essentially there is no single source of learning that can meet all kinds of needs the learning process. In other words, the selection of instructional media, need to be linked with the objectives to be achieved in the learning process. Especially in improving the visual thinking abilities of students, particularly in improving the ability of understanding the concept of using audio-visual learning media.

In this case the visual ability is very necessary to be improved. Therefore, in presenting the flat side of the room woke require visual media audio-visual even make it more interesting and the message conveyed more 
easily understood by students.

Teachers only provide learning regardless of the competency of the student, so that berpengruh towards visual thinking and response capabilities of students during the learning in the classroom. Besides, the problem is due to the media that is used in the learning process is not effective against the achievement of desired learning objectives. It is also confirmed from the results of interviews with several supervisors throughout subrayon 08 is Hardiansyah, P. Utauli Sinaga and Ahmad Khairul who supervised learning in some schools become surrogate, said: "The math teacher at subrayon 08 generally still using conventional learning models and rarely using instructional media "When asked the reason is the difficulty of making media, time constraints in teaching,

In response to the problems that arise in mathematics above which resulted in poor visual thinking abilities of students in mathematics, it is necessary for teachers and researchers choose the learning that can change the paradigm. One model that is effective and gives effect to the visual ability is a model of guided discovery.

Dahar (2011: 79) expressed the view that considers learning Bruner in accordance with the invention actively search for knowledge by humans and by itself gives the best results. Effendi (2012: 4) revealed that to produce an invention, the students should be able to connect mathematical ideas that they have. For example, students mereperentasikan these ideas through images, symbols, or words to be more simple and easy to understand. Familiarize students with learning inventions such as by applying a model of guided discovery, indirectly also familiarize students representing information, data or knowledge to produce an invention.

\section{LITERATURE REVIEW}

\subsection{Itself Teaching and Learning Mathematics}

In a general sense, learning is an activity that causes a relatively permanent change as a result of efforts done. According to Anthony (in Trianto, 2009: 15) learning is a process of creating a relationship between something that has been understood and something new, learning means not departing from a truly unknown (zero), but the linkage of the two knowledge existing with new knowledge.

Evidence that one has learned is a change in behavior on the person.Change is derived from experience.Hamalik (2009: 27) says that "learning is a modification or reinforce behavior through experience". This means that learning is a process, an activity and not a result or goal.

The nature of learning mathematics is a mental activity to understand the meaning and relationships as well as symbols, then the implementation of the real situation, namely that learning mathematics is concerned with what and how to use them in making decisions to solve the problem.

Gagne (in Hamzah, 2008: 105), suggests eight types of learning can be done procedurally or hierarchy in learning mathematics. These eight types of learning, namely (1) learn signal (signal learning), (2) studying stimulus response (stimulus-response learning), (3) study stringing behavior (behavior chaining learning), (4) learning verbal associations (verbal chaining learning), (5) study of discrimination (diskrimination learning), (6) to learn concepts (concept learning), (7) learning rule (rule learning), (8) to learn to solve problems (problem solving learning). Hierarchies first study four types of learning referred to as type (simple type of learning), while the four types of the latter type of hypothetical deductive learning (deduktive hipotetic learning). Gagne suggested that,

\subsection{Itself Media Assisted Learning Macromedia Flash 8.0}

Medium term derived from the Latin word is the plural of "medium", which literally means an intermediary or introduction.It is also in accordance with the opinion of Lesle J. Briggs (1979: 212-213) states that learning media as "a tool to stimulate students' learning process to occur. As for the effectiveness of the media, Brown (1970) underlines that the media used by teachers or students well can affect the effectiveness of teaching and learning. Based on the above opinion, it can be is developed some understanding of the position of the media and the role and contribution in pemebelajaran activities.

\subsection{The discovery Guided Learning Model in Mathematics}

The discovery is the translation of discovery. According to Sund "discovery is a mental process where students are able to assimilate something concepts or principles". The mental process is to observe, digest, understand, mengolong-divided, making allegations, explaining, measuring, make conclusions and so on (Roestiyah, 2001: 20). Meanwhile, according to Jerome Bruner "invention is a process, a path / way of approaching the problem rather than a specific product or item of knowledge". (Markaban, 2006: 9).

According to Johnson (Sumarno, 2003: 228) discovery learning is an attempt to gain insight and understanding deeper. Thorset, Petter., (2002) revealed the discovery learning is a learning situation in the which the principal content of what is to be learned is not given but must be Independently discovered by the student (method of the invention is a learning situation that in principle the students are not given the knowledge but the students have to find their own new thing).

From the above opinion can be concluded that the model of guided discovery deliberately designed to 
increase students' activity is greater, process-oriented, to find their own information necessary to achieve instructional goals. Thus the model of guided discovery and results-oriented process together.

\subsection{Visual Thinking Skills (Visual Thinking)}

visual Thinkingor Visual Thinking is an intellectual process intuitive and visual imagination ideas, either in mental imagery or through images (Brasseur, 1991: 130). Goldsmchmidt, 1994; Laseau, 1986) states rely on language thinking processes visual images, shapes, patterns, textures, symbols. However, Visual Thinking require more than the visualization or representation.John. B. Miner \& Stainer. G. A(1997) stated "It is a thrill to represent the structure of knowledge in the form of an idea, the idea can flow as images, diagrams, explanations of models, paintings set great ideas and simple solution.

According to Surya. E (2012) Visual Thinking can be defined as something active thinking and analytical process to understand, interpret and produce a visual message, the interaction between seeing, imagining, and describe it as a destination can be used, and such advanced verbal thinking. Zimmerman and Cunningham (1991) stated visualization is the process of image formation (mental, or with paper and pencil.

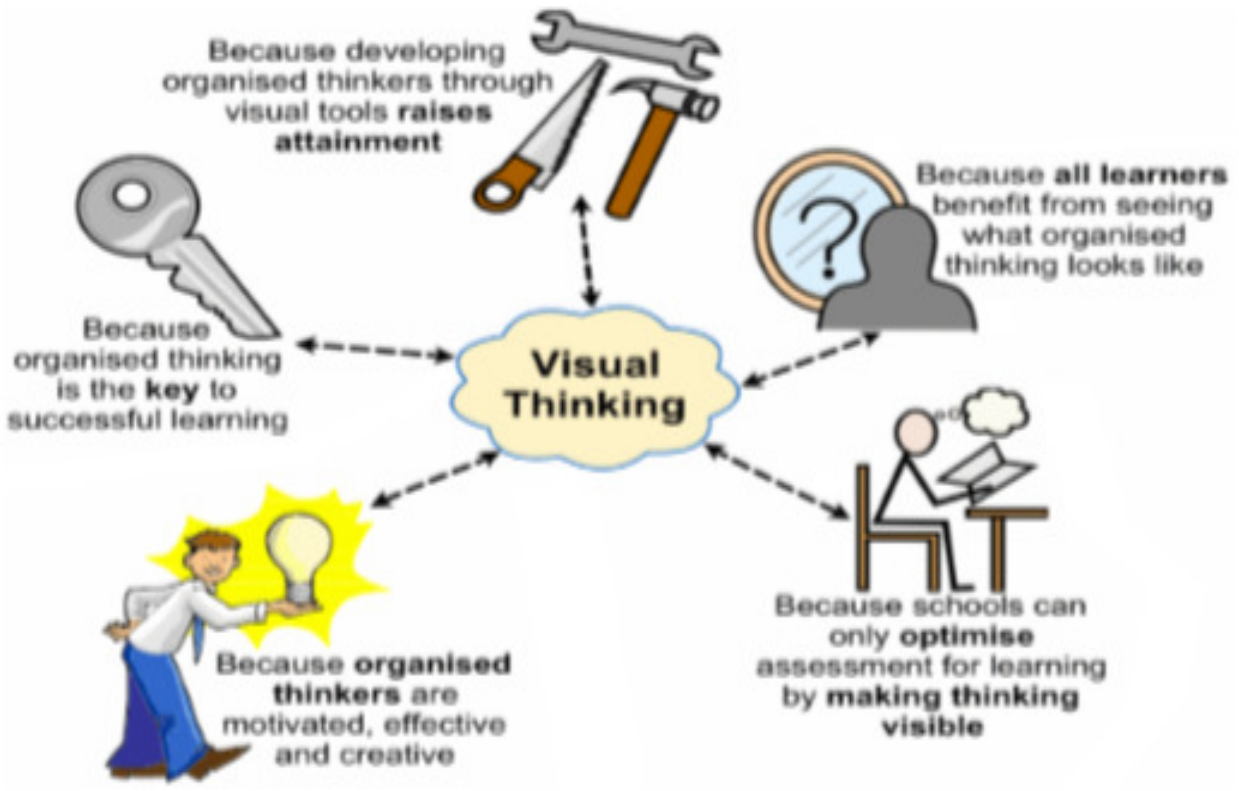

Picture. 1 visual thinking Why is it important?

Yin (2009) identifies the role of visualization: To understand the problem, simplify the problem, look at the issues related to connection, meet the individual learning styles, as a substitute for the calculation, as a means to check the answer, and to turn a problem into mathematical forms. Therefore, the role of visual thinking is very important and interwoven with guided discovery models, where students are taught with the model automatically guided discovery connected in solving problems assigned by the teacher in his own way.

\subsection{Learning materials}

Materials to learn the things that must be prepared by the teacher before implementing learning. Teachers should be able to design learning to achieve educational goals stated (Sapta, Hamid, and Syahputra, 2018). learning materials are the necessary ingredients and used in managing the learning process or tool that is very important for teachers to make learning efficient and to improve student achievement (Trianto 2011; Olayinka, 2016).

Guidance is given through a series of questions or give the student activity sheets. Thus, the use of guided discovery learning method can overcome the difficulties in the learning process to improve visual thinking skills in the material to build the flat side space (Cube and Beam) in SMPN 2 Morawa.

\section{RESEARCH METHODS}

This research was conducted in SMP Negeri 2 Morawa. The choice of location this study because researchers have to coordinate with the school principal of SMPN 2 Tanjung Morawa, related to the development of instructional media cube and block material. The population of this research is class VIII SMP Negeri 32 Tanjung Morawa. While the object of this research is the Macromedia Flash media assisted learning materials geometrical flat side (cubes and blocks) were developed. 


\subsection{Learning Media Development Procedure}

In the development of media-assisted learning of mathematics is used Macromedia Flash development model 4D (Four-D). According to Thiagarajan (1974), the research and development of 4D models terdisi on 4 main stages, ie define, design, develop, and disseminate. Data were analyzed quantitatively. The purpose of this research method is to determine the difference in improving the visual thinking as a junior high school student learning outcomes. increase students' visual thinking skills can be obtained from Sugiyono (2013) to calculate the validity of Visual Thinking Ability Test is Product Moment Correlation formula:

$$
r_{x y}=\frac{N \sum_{x y}-\left(\sum_{x}\right)\left(\sum_{y}\right)}{\sqrt{\left\{N \sum x^{2}-(x)^{2}\right\}\left\{N \sum y^{2}-\left(\sum y\right)^{2}\right\}}}
$$

\section{RESULTS}

\subsection{Description of Instructional Media Development Phase}

In this study, the effective learning media meets the criteria in the hearing II or in other words, the final draft was obtained in the trial II. Results Thiagarajan development of instructional media using 4-D model of evaluation are as follows:

\subsubsection{Define}

Based on the study on learning media in Tanjung Morawa 2 Public High School found several weaknesses in the material cubes and blocks used by the teacher, because the teacher has not developed the media in accordance with the characteristics of students, who did not discuss a matter of routine for the students, do not need to see contextually related with real life, and teachers do not use the SW as an aid to learning. In addition, in the learning process, teachers still use conventional learning in which students participate in the reconstruction of mathematical knowledge and not guided to find ideas in solving problems.

\subsubsection{Design}

At this stage an initial draft of LAS is produced during the three meetings and Media. All the results of the design phase is called the draft I.

\subsubsection{Develop}

In this validation stage of my design for media specialists and subject matter experts, and then conduct field trials. The goal is to see flaws in my design so that it can be revised and enhance learning media are developed. The results of expert validation of media and materials in the form of content validity assessment which showed that all study materials valid criteria, with the average value of the total validation of the lesson plan to 4.5; media validation by experts 4.63 learning materials; Validation Media Education by Learning Media Expert 4.67; and LAS 4.4. All the items tested visual thinking math skills of students meet the criteria for a valid and reliable. reliability of the instrument used to determine the results of the test. Based on the calculation, reliability mathematical thinking skills test capability is 075358 (very high category). After learning that developed media have valid criteria, learning media in the form of draft II was tested in the study site in Tanjung Morawa 2 Public High School as a trial I. Based on the test results of data analysis, it was found that the developed learning media does not meet all the criteria of an effective, so that improvements are made to produce learning materials that meet all the criteria of an effective set. This revision was based on the findings of the weakness of instructional media in the session I, namely to study implementation plans relating to the allocation of time to learn, and media related to the subject matter studied. Once the revision is completed,

\subsubsection{Disseminate}

Development of instructional media reached the final stage if it has a positive value of media experts and subject matter experts through development test. So learning media is then packaged, distributed and determined for a wider scale. But in this study was not carried out the deployment phase, so that the fourth stage is not described. The trial results I

Results Experiment I Based on analysis of experimental data, it was found that the developed learning media is not effective, because there are other indicators of effectiveness has not been reached. The results of classical completeness in visual thinking skills of mathematics students in the first trial, the average visual thinking skills students on the test results is equal to 68.89 in the medium category. It states that the student has not met the classical completeness value. Indicators of effectiveness is $85 \%$. Improving students' mathematical thinking skills first trial visible visual thinking skills visual average of $83.3 \%$ and incomplete was $16.7 \%$. From the data obtained in accordance with the criteria of completeness of student learning with a classic, ie at least $85 \%$ of students who take the test Visual Thinking ability was able to achieve a minimum of B-grades. Then the result of the ability of Visual Thinking has been finished in a classic way, as only $83.3 \%$ of students were able to achieve a B-score. So, it is testing the first application of media-assisted learning Macromedia, Flash was developed did not meet the requirements, suggestions, completeness, classic. Based on analysis of student responses in the table above, while $3.1 \%$ of students answered a negative answer. The result is positive, because 
more than $80 \%$ of students gave positive responses to the media Assisted Learning Macromedia Flash is developed. Then the result of the ability of Visual Thinking has been finished in a classic way, as only $83.3 \%$ of students were able to achieve a B-score. So, The trial is the first application of media-assisted learning Macromedia, Flash was developed did not meet the requirements, suggestions, completeness, classic. Based on analysis of student responses in the table above, while $3.1 \%$ of students answered a negative answer. The result is positive, because more than $80 \%$ of students gave positive responses to the media Assisted Learning Macromedia Flash is developed. Then the result of the ability of Visual Thinking has been finished in a classic way, as only $83.3 \%$ of students were able to achieve a B-score. So, it is testing the first application of mediaassisted learning Macromedia, Flash was developed did not meet the requirements, suggestions, completeness, classic. Based on analysis of student responses in the table above, while $3.1 \%$ of students answered a negative answer. The result is positive, because more than $80 \%$ of students gave positive responses to the media Assisted Learning Macromedia Flash is developed. classic. Based on analysis of student responses in the table above, while $3.1 \%$ of students answered a negative answer. The result is positive, because more than $80 \%$ of students gave positive responses to the media Learn to use Macromedia Flash is developed. classic. Based on analysis of student responses in the table above, while $3.1 \%$ of students answered a negative answer. The result is positive, because more than $80 \%$ of students gave positive responses to the media learn to use Macromedia Flash is developed. $1 \%$ of students answered a negative answer. The result is positive, because more than $80 \%$ of students gave positive responses to the media Learn to use Macromedia Flash is developed. classic. Based on analysis of student responses in the table above, while $3.1 \%$ of students answered a negative answer. The result is positive, because more than $80 \%$ of students gave positive responses to the media learn to use Macromedia Flash is developed. $1 \%$ of students answered a negative answer. The result is positive, because more than $80 \%$ of students gave positive responses to the media Learn to use Macromedia Flash is developed. classic. Based on analysis of student responses in the table above, while $3.1 \%$ of students answered a negative answer. The result is positive, because more than $80 \%$ of students gave positive responses to the media learn to use Macromedia Flash is developed.

\section{II trial results}

Results Experiment II Based on the analysis of data II trials, it was found that the developed learning media is effective based on indicators of the effectiveness of teaching materials that have been achieved. The results of classical completeness visual thinking skills of mathematics students in the hearing II, the average student test classical learning completeness students Visual Thinking is 31 students from 36 students, or about $86.1 \%$ of students were considered a classic finish. In accordance with the criteria of students' mastery of classical, $85 \%$ of students who took the test the ability of Visual Thinking is able to achieve a minimum grade of B. Then the results of the test Visual Thinking ability students have completed a classic, because there were $86.1 \%$ of students were able to achieve a minimum score of B. It can be concluded that the application of Macromedia assisted learning is a classical completeness assessment. Based on the result of the increase in students the ability Visual Thinking in the first and second test showed the average level of my test results Visual Thinking ability was 68.89 increased to 73.61 in the second session. Thus, it is the average value of the Student Visual Thinking ability 4.72. Learning indicators that have been supporting effective learning media in terms of completeness of classical learning, the students give a positive response to the media, and the time spent looking. Looking for data analysis I and II, a test derived from an average response of each trial was positive. It can be concluded that the application of Macromedia assisted learning is a classical completeness assessment. Based on the result of the increase in students the ability Visual Thinking in the first and second test showed the average level of my test results Visual Thinking ability was 68.89 increased to 73.61 in the second session. Thus, it is the average value of the Student Visual Thinking ability 4.72. Learning indicators that have been supporting effective learning media in terms of completeness of classical learning, the students give a positive response to the media, and the time spent looking. Looking for data analysis I and II, a test derived from an average response of each trial was positive. It can be concluded that the application of Macromedia assisted learning is a classical completeness assessment. Based on the result of the increase in students the ability Visual Thinking in the first and second test showed the average level of my test results Visual Thinking ability was 68.89 increased to 73.61 in the second session. Thus, it is the average value of the Student Visual Thinking ability 4.72. Learning indicators that have been supporting effective learning media in terms of completeness of classical learning, the students give a positive response to the media, and the time spent looking. Looking for data analysis I and II, a test derived from an average response of each trial was positive. Based on the result of the increase in students the ability Visual Thinking in the first and second test showed the average level of my test results Visual Thinking ability was 68.89 increased to 73.61 in the second session. Therefore, it is the average value of the Student Visual Thinking ability 4.72. Learning indicators that have been supporting effective learning media in terms of completeness of classical learning, the students give a positive response to the media, and the time spent looking. Looking for data analysis I and II, a test derived from an average response of each trial was positive. Based on the result of the increase in students the ability Visual Thinking in the first and second test showed the average 
level of my test results Visual Thinking ability was 68.89 increased to 73.61 in the second session. Thus, it is the average value of the Student Visual Thinking ability 4.72. Learning indicators that have been supporting effective learning media in terms of completeness of classical learning, students gave positive responses to the media, and the time spent looking. Looking for data analysis I and II, a test derived from an average response of each trial was positive. which is an average value of 4.72 Visual Thinking student ability. Learning indicators that have been supporting effective learning media in terms of completeness of classical learning, the students give a positive response to the media, and the time spent looking. Looking for data analysis I and II, a test derived from an average response of each trial was positive. which is an average value of 4.72 Visual Thinking student ability. Learning indicators that have been supporting effective learning media in terms of completeness of classical learning, students gave positive responses to the media, and the time spent looking. Looking for data analysis I and II, a test derived from an average response of each trial was positive. Each experiment has reached a predefined categories, which $\geq 80 \%$. Thus, it can be said that the use of media-assisted mathematics learning Macromedia developed to have an impact on improving the capabilities of Visual Thinking student

The use of Macromedia Flash Media Assisted Learning Ability To Enhance Visual Thinking

Based on analysis of visual thinking skills in I and II trials that showed an increased ability of the students. Visual Thinking upgrades can be seen from the average yield Visual Thinking ability tests obtained by the students. Improve the students' Visual Thinking also look at each Visual indicator Thinking ability. In the results, it can be seen that Improve Visual Thinking Ability highest on indicators paint and gifts. The increase in the average test results Visual Thinking ability students who obtained student with 68.89 in the session I improved to 73.61 in the second session. Improve Visual Thinking indicator of the ability of students obtained the painting indicators, followed indicator of the representation, operations, explain, and identify. In the research, seen that there is an increase relationship indicator, the decline in value is created. Based on this, the ability of Visual Indicator placed on the orientation indicator, while the most difficult indicators are indicators of operation. The same thing has been discussed in (2009) study of Lee who stated that learning to use the media to enhance the student's ability to think visually.

\section{CONCLUSION}

From the discussion above, it can be concluded that the ability to think visually math learning experience of students increased after using Macromedia Flash media. This study shows that learning mathematics is an important thing to consider in an effort to maximize the students' mathematics learning achievement. It is expected that mathematics teachers can use this learning media to make quality learning materials in learning mathematics in school.

\section{REFERENCES}

Brasseur, L. 1991. Visual Literacy in the Computer Age: A Perceptual Complex Landscape, Computers and Technical Communication: Pedagogical and Programmatic Perspectives, SA Selber (ed.), Ablex, Greenwich, pp. 75-96, 1997.

Brown., (1970). Strategies for Teaching Critical Thinking. Practical Assessment, Research \& Evaluation. Available: http: //edresearch.org/pare/getvn.asp? $\mathrm{v}=4 \& \mathrm{n}=3$.

Dahar, RW (2011). Theories of Learning. Jakarta. Erland.

Effendi, LA, (2012)., Learning Mathematics WITH Guided discovery method to review Upgrading Representations and Mathematical Problem Solving * Junior high school students. UPI Journal (Online), Vol. 13, No. 2, (http://jurnal.upi.edu/file/Leo_Adhar.pdf,

Hamalik, O. (2009). Teaching Based Planning System. Jakarta. Earth Literacy.

Hamzah., (2008)., Learning Model. Creating a Learning Process Creative and Effective. Jakarta: Earth Literacy. Hasratuddin. (2015). Why Should Learn Mathematics. Prime Publishing.

John. B. Miner \& Stainer. G. A (1997, Policy and Management Strategy, Jakarta. Publisher

Markaban. (2006). Mathematics Instructional Model Approach Guided discovery. Yogyakarta: Ministry of Education.

Roestiyah, NK (2001). Starategi Learning. Jakarta: Rineka Reserved.

Rusman. (2013), Grade School Management Series Models Developing Professional Teacher Education, Jakarta: King Grafindo Persada.

Sapta. A. Hamid. A., and Syahputra. E., (2018). Assistance of Parents In The Learning At Home. WMAMathcomtech 2018 IOP Publishing IOP Conf. Series: Journal of Physics: Conf. Series 1114 (2018) 012020 doi: 10.1088 / 1742-6596 / 1114/1/012020

Sugiyono (2013). Statistics Research and Applications with SPSS10.0 for Windows. Bandung: Alfabeta

Sujono., (1988). Teaching Mathematics for Secondary Schools. Jakarta: Ministry of Education and Culture Directorate General of Higher Education Institutions Development Project Personnel.

SUMARMO, U. 2013. Evaluation in Learning Mathematics. FPMIPA UPI 
Sun. E., A (2011). Visual Thinking In Mathematics Learning Maximizing Students Can Build National Character. Googlescholer (Online). (Department of Mathematics Education Unimed).

Thiagarajan. S., Semmel, D. S \& Semmel, MI 1974. Instructional Development for Training Teachers of expectional Children. Minneapolis. Minnesota: Leadership Training Institute / Special Education: University of Minnesota.

Trianto. (2011). Designing Innovative-Progressive Learning Model. Jakarta: Kencana.

Trowbridge, Leslie W, Bybee, Rodger. W, \& Carlson Powell, Janet. (2004). Teaching Secondary School Science: Strategies for Developing Scientific Literacy. United States: Person Education 